A $\underset{\text { publications }}{\mathrm{C}} \mathrm{G}$ Rec. Nat. Prod. 15:2 (2021) 111-121

records of natural

products

\title{
Essential Oils of Three Hypericum Species from Colombia: Chemical Composition, Insecticidal and Repellent Activity Against Sitophilus zeamais Motsch. (Coleoptera: Curculionidae)
}

\author{
William R. Patiño-Bayona $\bigodot^{1}$, Erika Plazas ${ }^{1}$, Jenifer J. Bustos-Cortes ${ }^{1}$, \\ Juliet A. Prieto-Rodríguez $\oplus^{2}$ and Oscar J. Patiño-Ladino $\oplus^{1 *}$
}

\author{
${ }^{1}$ Department of Chemistry, Faculty of Sciences, Universidad Nacional de Colombia-Sede Bogotá, \\ 111321 Bogotá, Colombia \\ ${ }^{2}$ Department of Chemistry, Faculty of Sciences, Pontificia Universidad Javeriana-Sede Bogotá, \\ 110231 Bogotá, Colombia
}

(Received May 24, 2020; Revised July 15, 2020; Accepted August 01, 2020)

\begin{abstract}
The maize weevil (Sitophilus zeamais) is one of the main insect responsible of significant losses in stored products, and to keep nutritional value of them to find effective and safe solutions are very important. The Hypericum genus might be a potential source of new bio-insecticides due to the chemical composition of essential oils. In this study, components of essential oils of three Hypericum species were investigated for first time by Gas Chromatography-Mass Spectrometry (GC-MS) and, fumigant and contact toxicities as well as the repellent activity of essential oils of them were evaluated against $S$. zeamais adults. While the main components in $H$. mexicanum oil were determined as $n$-nonane $(53.08 \%)$ and $\alpha$-pinene $(25.28 \%)$, the major constituents were determined as $\alpha$-pinene $(45.52 \%)$ and $\beta$-caryophyllene $(13.59 \%)$ in the essential oil of $H$. myricariifolium. Chemical composition of essential oil of $H$. juniperinum were found to be $n$-nonane $(12.0 \%), \alpha$-pinene $(8.25 \%)$, geranyl acetate $(7.93 \%)$, and $\beta$-caryophyllene $(13.60 \%)$. The results revealed that $H$. mexicanum and $H$. myricariifolium oils have fumigant toxicity $\left(\mathrm{LC}_{50}<500 \mu \mathrm{L} / \mathrm{L}\right.$ air) and a potential action as repellents $(\mathrm{RP}>70 \%$ at $6.2-22.7 \mu \mathrm{L} / \mathrm{L}$ air) for the control of the pest.
\end{abstract}

Keywords: Sitophilus zeamais; essential oil; repellent; Hypericum mexicanum; Hypericum myricariifolium; Hypericum juniperinum. (C) 2020 ACG Publications. All rights reserved.

\section{Introduction}

The maize weevil (S. zeamais), is one of the major pests of stored products that affect different commodities important for food security, included maize, rice, sorghum, wheat and among others. The negative impact attributed to this pest is principally due to their high reproduction rate and with the possibility of larvae and adults to damage the grains $[1,2]$. This primary pest can damage shelled grains, creating holes and reducing them to powder. Besides, it can cause a loss in germination ability and nutritional quality of the grains [3,4]. The control of this kind of insects is performed by use of synthetic pesticides such as methyl bromide and phosphine [5]. However, the indiscriminate application of synthetic products has led to serious problems such as toxic residues in the products, environment

\footnotetext{
*Corresponding author: E-Mail: ojpatinol@ unal.edu.co; Phone: +57 13165000 Ext 14485
} 
pollution and has led to the increased resistances of pests [6,7]. Thus, the development of new chemical control strategies with less environmental impact and high effectivity is necessary.

The essential oils (EOs) are a promissory source of bioinsecticides due to the chemical diversity of their secondary metabolites, among which monoterpenes, sesquiterpenes, phenylpropanoids and hydrocarbons predominate $[8,9,10]$. This variety in terms of composition, added to lipophilicity and high volatility, allows EOs to present several entrance modes to the insect and, therefore, exert different modes of insecticide action [11, 12]. Most EOs are highly effective as repellents, and others are toxic by direct contact or penetration into the body by the respiratory route [13, 14]. The EOs have also shown insecticidal actions such as inhibition of molting, reduction in growth and fecundity, cuticle disruption, and effects on the invertebrate octopamine pathway $[15,16]$. Other EOs affect the nutritional physiology of insects, either by modifying their behaviour or by producing toxic effects after ingestion $[17,18]$.

Hypericum genus is composed of shrubs or herbs that usually possess secretory structures present in both the vegetative and reproductive organs; among them are translucent glands containing considerable amounts of EOs [43,44]. Many species are native to high mountain regions of Andes in Central and South America, where a complex mixture of habitats occurs in Paramo. Due to the particular zones where Hypericum species grow, they possess the ability to biosynthesize a wide variety of defensive secondary metabolites. Even though many species of the genus highlighted their medicinal properties like anti-oxidant, anti-inflammatory, anti-depressant and anti-nociceptive [18, 45, 46], several studies has been reported on their effectiveness as insecticides $[19,18,20]$. Lipophilic extract obtained from the aerial parts of $H$. polyanthemum showed larvicidal activity and inhibited the pupae formation of Aedes aegypti [19]. Regarding to those reports against stored-product pests, H. scabrum oil was found to be toxic by fumigation on adults of Bruchus dentipes [18]; meanwhile, EO from H. hyssopifolium showed promissory fumigant toxicity against Sitophilus oryzae and Tribolium confusum [20].

In Colombia, studies of the bioactivity and secondary metobolite profile of few alcoholic extracts of Hypericum species have been reported. Methanol extract and butanol fractions of $H$. juniperinum showed antidepressant effects [21], and ethanol extracts of $H$. mexicanum, $H$. myricariifolium and $H$. juniperinum exhibited high inhibitory activity against Staphylococcus aureus and Staphylococcus epidermidis, and those extracts are mainly composed by phenolics such as flavonoids, tannins and quinones, as well as saponins [21,22]. Even though the species in current study have been subjected to preliminary investigations, none of them has focused on the study of the chemical composition of their essential oils and insecticidal activities. Therefore, this study was designed with the objective to determine the chemical composition of the EOs extracted from these three Hypericum species and evaluate the insecticidal activity of the oils against $S$. zeamais adults.

\section{Materials and Methods}

\subsection{Plant Material}

The aerial parts of $H$. mexicanum L., H. juniperinum Kunth and $H$. myricariifolium Hieron, were collected at 3542 masl on the Usme-Sumapaz road, Cundinamarca, Colombia. The voucher specimens rest in the herbarium of the "Jardín Botánico José Celestino Mutis" with the numbers JBB10659, JBB00348 and JBB00350, respectively.

\subsection{Extraction of Essential Oils}

The aerial parts (fresh leaves and branches) of the three plants collected were subjected to steam extraction for 2 hours. The EOs were recovered by condensation using a Clevenger-type apparatus and after decantation they were dried with anhydrous sodium sulfate and stored in amber sealed glass bottles at $4{ }^{\circ} \mathrm{C}$ until use. 


\subsection{Chemical Composition of Essential Oils}

\subsubsection{Sample Preparation}

A volume of $25 \mu \mathrm{L}$ of each EO was taken and brought to a final volume of $1 \mathrm{~mL}$ with $\mathrm{n}$-hexane or dichloromethane. The standard hydrocarbon solution was prepared by dissolving $25 \mu \mathrm{L}$ of a homologous hydrocarbon solution $\left(\mathrm{C}_{8}-\mathrm{C}_{26}\right)$ to a final volume of $1 \mathrm{~mL}$ with $n$-hexane.

\subsubsection{Analysis by GC-MS}

The chromatographic analysis was performed using an Agilent Tecnologies 6850 II series gas chromatograph with selective mass detector Agilent Technologies MSD5975B, which was operated at $70 \mathrm{eV}$, using a quadrupole analyzer, in full scan mode at $4.57 \mathrm{scan} \mathrm{s}^{-1}$. Mass spectra were acquired between 40 and $400 \mathrm{~m} / z$. The analysis was performed with two orthogonal polarity columns (DB-5MS and HP-INNOWax).

In the first analysis, a DB-5MS column ((5\%-phenyl)-methylpolysiloxane, $60 \mathrm{~m} \mathrm{x} 0.25 \mathrm{~mm} \mathrm{x}$ $0.25 \mu \mathrm{m})$ was used with injection in Split mode $(20: 1)$ for $1.5 \mathrm{~min}$. The temperature ramp started at $40{ }^{\circ} \mathrm{C}$ for $2 \mathrm{~min}$, then it was increased to $123^{\circ} \mathrm{C}\left(4^{\circ} \mathrm{C} / \mathrm{min}\right)$ and remained constant for $2 \mathrm{~min}$. Afterward increased to $160{ }^{\circ} \mathrm{C}\left(4^{\circ} \mathrm{C} / \mathrm{min}\right)$ remained constant $5 \mathrm{~min}$, subsequently increased to $220^{\circ} \mathrm{C}\left(5^{\circ} \mathrm{C} / \mathrm{min}\right)$ and kept constant for $8 \mathrm{~min}$. Finally, it was increased to $280{ }^{\circ} \mathrm{C}\left(5^{\circ} \mathrm{C} / \mathrm{min}\right)$ keeping it constant $4 \mathrm{~min}$, for a total run time of $75 \mathrm{~min}$. In the second analysis a HP-INNOWax column (polyethylene glycol (PEG), $60 \mathrm{~m} \times 0.25 \mathrm{~mm} \times 0.25 \mu \mathrm{m}$ ) was used with injection in Split mode (20: 1) for $1.5 \mathrm{~min}$. The temperature ramp started at $45{ }^{\circ} \mathrm{C}$ for $4 \mathrm{~min}$, then it was increased to $120{ }^{\circ} \mathrm{C}\left(3{ }^{\circ} \mathrm{C} / \mathrm{min}\right)$ remained constant for $2 \mathrm{~min}$. Finally, it was increased to $250{ }^{\circ} \mathrm{C}\left(4^{\circ} \mathrm{C} / \mathrm{min}\right)$ keeping it constant $8 \mathrm{~min}$, for a total time of $71.5 \mathrm{~min}$. The injection volume used in each analysis was $1 \mu \mathrm{L}$.

\subsubsection{Determination of Chemical Composition of Essential Oil}

The chemical constituents were determined by comparing the mass spectra and retention indices obtained for each compound with those reported in NIST 14.L, Wiley 8.1 and Pherobase databases, as well as those published in the literature [23-25]. The Relative Retention Index (RRI) were calculated using a homologous series of hydrocarbons from $\mathrm{C}_{8}$ to $\mathrm{C}_{26}$, eluted under the same operational conditions described for EOs [24].

\subsection{Bioassays}

\subsubsection{Insects}

S. zeamais adults were obtained from a colony maintained in the research group Química de Productos Naturales Vegetales Bioctivos (QuiProNaB) of the Chemistry Department of the Universidad Nacional de Colombia - Bogotá. The adults were kept in corn mixtures of ICA variety 508 and yellow corn ICA variety, arranged in a culture chamber under conditions of darkness, humidity $(65 \pm 5 \% \mathrm{RH})$ and temperature controlled $\left(27 \pm 1{ }^{\circ} \mathrm{C}\right)$ [26]. Adult insects between 6-10 days after emergence were used in the different activity tests.

\subsubsection{Preliminary Insecticidal Activity}

The preliminary insecticidal activity of the EOs was determined by the "vial in vial" method reported in the literature [27]. A volume of $11 \mu \mathrm{L}$ of EOs was applied to a $2 \mathrm{~cm}$ diameter Wathman ${ }^{\circledR}$ No. 1 filter paper placed on top of a $1.5 \mathrm{~mL}$ glass vial. Subsequently, the vial was introduced into a 22 $\mathrm{mL}$ vial with screw-type closure containing 10 insects without sexing, leaving a final concentration of essential oil of $500 \mu \mathrm{L} / \mathrm{L}$ air. As positive controls, Nuvan $50 \AA$ containing dichlorvox as active ingredient $\left(100 \mu \mathrm{L} / \mathrm{L}\right.$ air) and Fosfamin ${ }^{\circledR}$ with phosphine as active ingredient $(150 \mu \mathrm{L} / \mathrm{L}$ air $)$ were used. The negative control was applied out in the same way, but without the addition of any substance. All tests were performed in triplicate under controlled temperature and humidity conditions $\left(27 \pm 1^{\circ} \mathrm{C}\right.$ y $65 \pm 5$ 
$\%$ HR). Insect mortality was determined at 24 hours. The insects were considered dead when no observed movement after stimulation for $15 \mathrm{~s}$ with an entomological pin. The percentage of mortality was calculated using the Abbott's [28] correction formula: Mortality $(\%)=[(\% \mathrm{Mt}-\% \mathrm{Mc}) / 100-\% \mathrm{Mc}]$ $* 100$, were $\mathrm{Mt}=$ mortality on treatment and $\mathrm{Mc}=$ mortality of control.

\subsubsection{Fumigant Activity Test}

The fumigant activity test was carried out similarly to the test described above, except that insect contact with the EOs was avoided. To avoid contact, the vial in which the paper impregnated with EO was placed, was covered with sheer curtain. The same conditions of the previous trial were reproduced to evaluate the EOs: $11 \mu \mathrm{L}(500 \mu \mathrm{L} / \mathrm{L}$ air $)$ of EO and 24-hour mortality reading. The percentage of mortality was calculated using the Abbott's correction formula. To obtain the results that allowed estimating the LC50, different quantities of EOs were used (oils quantities between 1.1 - $18 \mu \mathrm{L}$ for obtain concentrations between $50-818 \mu \mathrm{L} / \mathrm{L}$ air). All treatments were performed in quintupled under the same temperature and humidity conditions [29].

\subsubsection{Topical Contact Toxicity Test}

The contact toxicity was determined by the topical contact method, which consists of applying different amounts of EOs $(0.10,0.15$ and $0.20 \mu \mathrm{L})$ on the insect's prothorax [30]. Untreated insects were used as negative control and commercial product Nuvan $50 \AA$ was used as positive control at a volume of $0.10 \mu \mathrm{L}$. The treated insects were transferred to $22 \mathrm{~mL}$ glass vials, leaving 10 insects per vial. The vials were kept in the culture chamber under controlled temperature and humidity conditions $\left(27 \pm 1{ }^{\circ} \mathrm{C}\right.$ and $65 \pm 5 \% \mathrm{RH})$. All treatments were performed in triplicate and insect mortality was determined at 24 hours. Mortality percentages were calculated using the Abbott's correction formula.

\subsubsection{Repellent Activity Test}

The repellent action was tested using an olfactometer, consisting of two $290 \mathrm{~mL}$ bottles connected by a tube with a container located in the central part of the duct [31]. In one of the bottles, corresponding to the treatment, was placed a $1.5 \mathrm{~mL}$ vial that had a $2 \mathrm{~cm}$ diameter Whatman ${ }^{\circledR}$ No. 1 paper disc impregnated with different volumes of EO, corresponding to concentrations between 6.2 $22.7 \mu \mathrm{L} / \mathrm{L}$ of air. In the other bottle, was placed a $1.5 \mathrm{~mL}$ vial with the paper without $\mathrm{EO}$, and this acted as a control. Adult $S$. zeamais insects ( 20 per assembly) were incorporated through the central container of the connecting tube. The activity reading was done at 2, 6 and 24 hours after the application and the number of insects present in both containers (treated and untreated) were recorded. All treatments were performed in triplicate and the repellency percentage $(\mathrm{RP})$ was calculated as $\mathrm{RP}=[(\mathrm{N}-\mathrm{C}) /(\mathrm{N}+\mathrm{C})]^{*} 100$, were $\mathrm{N}=$ number of insects present in the untreated area and $\mathrm{C}=$ number of insects in the treated area.

\subsection{Statistical Analysis}

The results of the tests are presented as mean \pm standard error. Statistical significance was determined by the Tukey tests and an analysis of variance (ANOVA) was performed to determine whether results obtained for insecticidal activity assays were statistically different. Statistical significance was set at $\mathrm{P}<0.05$. For EOs with fumigant potential $\mathrm{LC}_{50}$ was estimated using the fumigant method and the Probit model.

\section{Results and Discussion}

\subsection{Chemical Composition}

The GC-MS analysis with orthogonal polarity columns of the three EOs allowed identifying 51 compounds corresponding to $65-95 \%$ of the total composition (Table 1). The EOs presented in their chemical composition mainly monoterpenes (30.9-54.7\%), sesquiterpenes (27.8-33.7\%) and aliphatic hydrocarbons (23.11-57.6\%). 
Table 1. Chemical composition of EOs from the three Hypericum species.

\begin{tabular}{|c|c|c|c|c|c|c|c|c|}
\hline \multirow{3}{*}{$\mathbf{N}^{\circ}$} & \multirow{3}{*}{ Components } & \multicolumn{4}{|c|}{$\begin{array}{r}\text { RRI } \\
\end{array}$} & \multicolumn{3}{|c|}{ Relative \% } \\
\hline & & \multicolumn{2}{|c|}{ Non-polar DB-5MS } & \multicolumn{2}{|c|}{ Polar (HP-INNOWax) } & \multirow{2}{*}{ HME } & \multirow{2}{*}{ HMY } & \multirow{2}{*}{ HJU } \\
\hline & & Exp. & Range(Ref) & Exp. & Range(Ref) & & & \\
\hline 1 & octane & 797 & 800 & - & - & 0.36 & - & 0.18 \\
\hline 2 & 2-methyloctane & 866 & $858-872$ & - & - & - & 0.54 & 3.82 \\
\hline 3 & nonane & 904 & 900 & - & - & 53.08 & 1.59 & 12.00 \\
\hline 4 & $\alpha$-thujene & 928 & 931 & 1026 & $1012-1039$ & 0.08 & 0.05 & - \\
\hline 5 & $\alpha$-pinene & 939 & $910-944$ & 1023 & $1000-1040$ & 25.28 & 45.52 & 8.25 \\
\hline 6 & $\alpha$-fenchene & 955 & $943-951$ & 1055 & $1045-1054$ & - & 0.05 & - \\
\hline 7 & canphene & 956 & $929-968$ & 1064 & $1040-1083$ & - & 0.28 & - \\
\hline 8 & 3-methylnonane & 971 & $970-977$ & 976 & $966-976$ & 1.24 & 0.49 & - \\
\hline 9 & sabinene & 976 & $973-976$ & 1119 & $1123-1147$ & 0.32 & - & - \\
\hline 10 & $\beta$-pinene & 983 & $960-990$ & 1105 & $1096-1120$ & 3.60 & 2.86 & 0.92 \\
\hline 11 & myrcene & 990 & $969-993$ & 1172 & $1150-1176$ & 1.11 & 1.67 & 3.94 \\
\hline 12 & decane & 1000 & 1000 & 1000 & 1000 & 0.13 & - & 0.12 \\
\hline 13 & $\alpha$-terpinene & 1020 & $1012-1020$ & 1184 & $1178-1223$ & - & 0.07 & - \\
\hline 14 & $p$-cymene & 1028 & 1014-1034 & 1279 & $1261-1290$ & 0.14 & 0.55 & - \\
\hline 15 & limonene & 1033 & $1031-1039$ & 1205 & $1198-1234$ & 0.28 & 1.90 & 0.79 \\
\hline 16 & cis $\beta$-ocimene & 1035 & $1023-1050$ & 1242 & $1242-1252$ & - & 1.12 & - \\
\hline 17 & $\beta$-phellandrene & 1036 & $1017-1043$ & 1215 & $1195-1222$ & 0.05 & - & - \\
\hline 18 & trans- $\beta$-ocimene & 1046 & $1039-1061$ & 1259 & $1242-1261$ & - & 0.22 & - \\
\hline 19 & $\gamma$-terpinene & 1060 & $1030-1078$ & 1253 & $1221-1262$ & - & 0.23 & 0.27 \\
\hline 20 & 2-methyldecane & 1062 & $1062-1077$ & 1051 & $1053-1057$ & 0.07 & - & - \\
\hline 21 & $\alpha$-terpinolene & 1087 & $1063-1104$ & 1291 & $1275-1297$ & - & 0.21 & 0.09 \\
\hline 22 & undecane & 1097 & 1099 & 1094 & $1099-1100$ & 2.72 & 0.65 & 0.44 \\
\hline 23 & nonanal & 1099 & $1082-1108$ & 1402 & $1382-1415$ & - & - & 2.25 \\
\hline 24 & $\gamma$-terpineol & 1199 & $1188-1207$ & 1696 & $1684-1695$ & - & - & 0.15 \\
\hline 25 & decanal & 1207 & $1186-1207$ & 1508 & $1495-1517$ & - & 0.54 & 3.27 \\
\hline 26 & anethole & 1289 & $1284-1301$ & 1846 & $1819-1847$ & - & - & 0.31 \\
\hline 27 & 2-undecanone & 1291 & $1291-1298$ & - & - & - & - & 1.03 \\
\hline 28 & geranyl acetate & 1381 & $1363-1383$ & 1768 & $1755-1778$ & - & - & 7.93 \\
\hline 29 & cyclosativene & 1371 & $1367-1371$ & 1489 & $1479-1492$ & 0.37 & - & - \\
\hline 30 & $\alpha$-copaene & 1385 & $1365-1394$ & 1500 & $1485-1509$ & 0.41 & - & 0.16 \\
\hline 31 & $\beta$-cubebene & 1396 & $1389-1393$ & 1548 & $1542-1558$ & 0.22 & - & - \\
\hline 32 & $\alpha$-santalene & 1424 & $1405-1435$ & 1581 & $1555-1601$ & 0.40 & 0.38 & - \\
\hline 33 & $\beta$-caryophyllene & 1430 & $1418-1451$ & 1610 & $1589-1617$ & 2.01 & 13.59 & 13.60 \\
\hline 34 & trans- $\alpha$-bergamotene & 1436 & $1422-1452$ & 1594 & $1536-1595$ & - & 0.86 & - \\
\hline 35 & trans- $\beta$-farnesene & 1450 & $1442-1457$ & 1679 & $1646-1674$ & - & 0.26 & - \\
\hline 36 & $\alpha$-caryophyllene & 1465 & $1444-1465$ & 1687 & $1672-1702$ & 0.46 & 4.69 & 6.06 \\
\hline 37 & $\gamma$-selinene & 1481 & $1438-1484$ & 1692 & $1682-1697$ & - & 0.64 & - \\
\hline 38 & $\alpha$-curcumene & 1485 & $1469-1500$ & 1786 & $1772-1798$ & - & 1.46 & - \\
\hline 39 & eremophilane & 1498 & $1486-1493$ & - & - & 0.06 & - & - \\
\hline 40 & $\alpha$-zingiberene & 1499 & $1448-1495$ & 1734 & 1728 & - & 1.34 & - \\
\hline 41 & $\beta$-selinene & 1501 & $1492-1511$ & 1749 & $1715-1749$ & 0.32 & 3.09 & - \\
\hline 42 & $\alpha$-Farnesene & 1504 & $1495-1509$ & 1731 & $1695-1748$ & 0.10 & - & - \\
\hline 43 & cis- $\alpha$-bisabolene & 1505 & $1500-1511$ & 1741 & $1719-1759$ & - & 2.40 & - \\
\hline 44 & $\alpha$-selinene & 1508 & $1463-1510$ & 1750 & $1701-1750$ & 0.51 & 2.50 & - \\
\hline 45 & $\beta$-bisabolene & 1514 & $1503-1517$ & 1740 & $1724-1748$ & - & 0.85 & - \\
\hline 46 & $\gamma$-bisabolene & 1519 & $1515-1530$ & 1769 & $1758-1773$ & - & 0.24 & - \\
\hline 47 & $\delta$-cadinene & 1527 & $1523-1530$ & 1771 & $1760-1786$ & 0.46 & 0.07 & - \\
\hline 48 & calamenene & 1532 & $1510-1532$ & 1849 & $1826-1839$ & 0.14 & - & - \\
\hline 49 & $\beta$-sesquiphellandrene & 1532 & $1516-1531$ & 1781 & $1748-1783$ & - & 0.37 & - \\
\hline 50 & 7-epi- $\alpha$-selinene & 1534 & $1526-1540$ & 1779 & $1775-1789$ & - & 0.94 & - \\
\hline 51 & cembrene A & 1834 & 1916-1929 & 2207 & $2207-2180$ & 1.38 & 1.13 & - \\
\hline \multicolumn{6}{|c|}{ Total monoterpenes (\%) } & 30.86 & 54.73 & 14.41 \\
\hline \multicolumn{6}{|c|}{ Total sesquiterpenes (\%) } & 5.46 & 33.68 & 27.75 \\
\hline \multicolumn{6}{|c|}{ Diterpenes $(\%)$} & 1.38 & 1.13 & - \\
\hline \multicolumn{6}{|c|}{ Phenylpropanes (\%) } & - & - & 0.31 \\
\hline \multicolumn{6}{|c|}{ Total hydrocarbons (\%) } & $\mathbf{5 7 . 6 0}$ & 3.81 & 23.11 \\
\hline & & 1 identi & ed $(\%)$ & & & 95.30 & 93.35 & 65.58 \\
\hline & & $\operatorname{ty}\left(20^{\circ}\right.$ & $(\mathrm{g} / \mathrm{mL})$ & & & 0.775 & 0.852 & 0.864 \\
\hline
\end{tabular}

RRI: Relative retention indices calculated against n-alkanes; Ref: the NIST WebBook; Pherobase Kovats Index [23,25]; Relative \%: calculated from MS data. HME: H. mexicanum; HMY: H. myricariifolium; HJU: H. juniperinum 
The major constituents of $H$. mexicanum oil were n-nonane (53.08\%) and $\alpha$-pinene $(25.28 \%)$, meanwhile for $H$. myricariifolium oil were $\alpha$-pinene $(45.52 \%)$ and $\beta$-caryophyllene $(13.59 \%)$. In the case of $H$. juniperinum, the majority components were n-nonane (12.00\%), $\alpha$-pinene $(8.25 \%)$, geranyl acetate $(7.93 \%), \beta$-caryophyllene $(13.60 \%)$, and $\alpha$-caryophyllene $(6.06 \%)$. The chemical composition of the OEs from aerial parts of $H$. mexicanum, $H$. myricarifolium and $H$. juniperinum were reported for the first time in this study.

The results of the essential oil composition of the studied Hypericum species are in agreement with previously reported data. Chemotaxonomic evaluation of the genus reveals that the main chemical constituents of the genus are aliphatic hydrocarbons, monoterpenes and sesquiterpenes. Hydrocarbons tend to be of the important metabolites in essential oils from species of the genus Hypericum and that makes them different from EOs obtained from other aromatic species [32, 33, 34].

\subsection{Insecticidal and Repellent Activity Against S. zeamais}

Firstly, screening of fumigant toxicities of the species were performed at the maximum concentration of $500 \mu \mathrm{L} / \mathrm{L}$ air (Figure 1) in order to determine the insecticidal potential of them against S. zeamais adults. Essential oils of $H$. mexicanum and $H$. myricariifolium were found promissory with higher mortality values (45\%). Meanwhile $H$. juniperinum oil does not have insecticidal activity against S. zeamais since it caused a mortality percentage lower than $10 \%$.

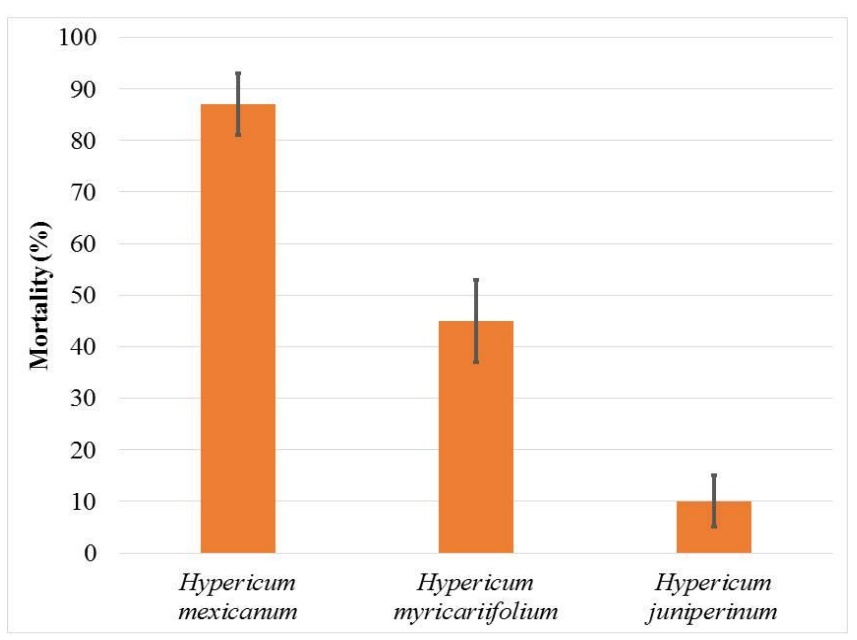

Figure 1. Results of preliminary screening of insecticidal activity of EOs from three species of the Hypericum genus

Taking into account that $S$. zeamais can climb the walls of the vial and come into contact with the paper impregnated with the treatment, a modified fumigant test and a topical contact assay were carried out with the two active EOs. This, in order to verify if the observed effect was only due to the fumigant action or had influence by contact. The fumigant toxicity results against $S$. zeamais adults are shown in Figure 2. The H. mexicanum oil produced very strong fumigant toxicity (the mortality reach to $94 \%$ at $500 \mu \mathrm{L} / \mathrm{L}$ air), whilst $H$. myricariifolium oil showed a low level of $56.0 \%$ ( $500 \mu \mathrm{L} / \mathrm{L}$ air) (See supporting information for details). These results may be attributed to the high content of volatile metabolites such as n-nonane and $\alpha$-pinene, which can enter on the body of the insect through the spiracles generating mortality by fumigance [29]. Some reports indicate that linear and branched alkanes have insecticidal effects on the insects of Diptera, Lepidoptera, and Coleoptera orders [35, 36, 37]. On the other hand, the $\alpha$-pinene has been reported as a potential fumigant against $S$. zeamais with $\mathrm{LC}_{50}$ of $6.41 \mathrm{mg} / \mathrm{L}$ [38], allowing attributed a part of the fumigant toxicity of EOs to this monoterpene. Table 2 shows the fumigant toxicity of the oils, in terms of their $\mathrm{LC}_{50}$, as well as the slope, intercept, and significance values (P-value). Between the two oils, the one obtained from H. mexicanum is the most promising, since it had a moderate lethal concentration $(223.5 \mu \mathrm{L} / \mathrm{L}$ air $)$ and the highest "slope" value, 
a fact that indicates that do not require large variations in their concentration to significantly increase insect mortality.

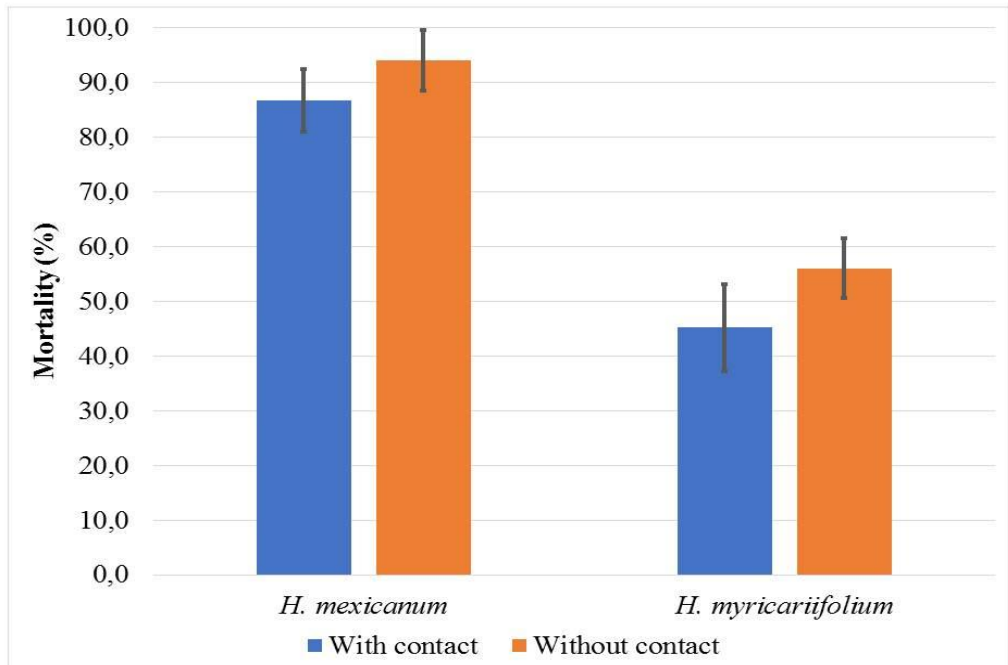

Figure 2. Fumigant activity results of "vial in vial" methods with and without contact

Table 2. Lethal concentrations and linear parameters

\begin{tabular}{|c|c|c|c|c|}
\hline Species & $\begin{array}{c}L^{L C_{50}}(\mu \mathrm{L} / \mathrm{L}) \\
(95 \% \text { Confidence limit) }\end{array}$ & Slope & Intercept & $P$-value \\
\hline H. mexicanum & $223.5(173.6-262.0)$ & 0.005 & -1.14 & $1.60 \times 10^{-13}$ \\
\hline H. myricariifolium & $463.1(338.3-559.9)$ & 0.002 & -0.779 & $2.10 \times 10^{-13}$ \\
\hline
\end{tabular}

Regarding to contact toxicity data, with doses between 0.10 to $0.20 \mu \mathrm{L} /$ insect, mortalities of 0 , 33.33 and $36.67 \%$ were obtained for $H$. myricariifolium oil, while no response was observed with $H$. mexicanum oil (Figure 3). Since contact toxicity occurs when the insecticide, due to its lipophilic nature, penetrates the cuticle of the insect until reaching the white site or creates an impermeable film causing death by suffocation [39], just the less volatile metabolites can generate this effect. The oil from $H$. myricariifolium has a considerable amount of $\beta$-caryophyllene (13.59\%), sesquiterpene that has been evaluated by contact against $S$. zeamais with promising results $[1,38]$, so the activity observed could be associated with this compound.

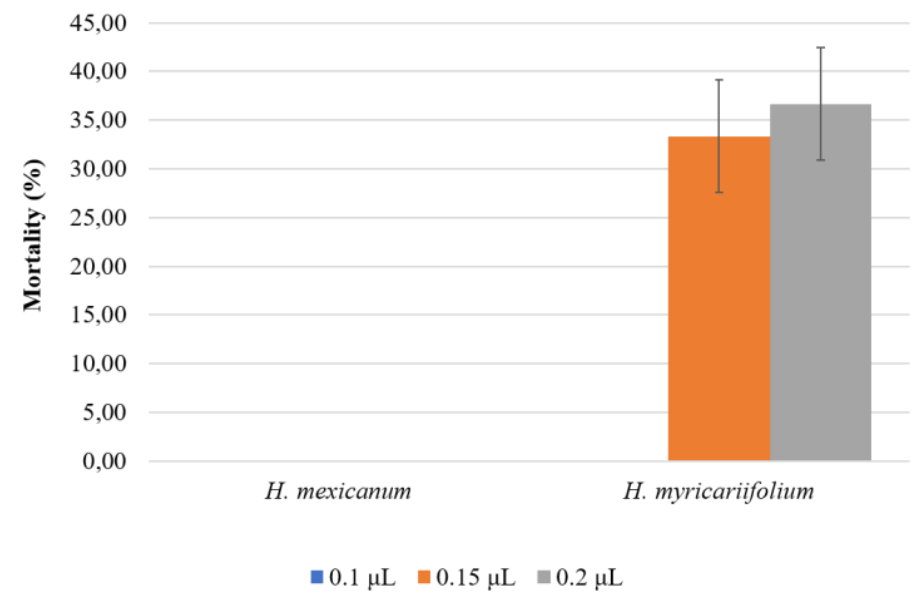

Figure 3. Contact toxicity results against $S$. zeamais of EO from active species of the Hypericum genus 
To evaluate the repellent potential of the $H$. mexicanum and $H$. myricariifolium oils an olfactometer method was used. According to the scale reported by Kosini and collaborators [40], at the evaluated concentrations, in the three tested times, the oils behave like strong repellents, with a repellency rate $>70 \%$ and follow a constant dose-response relationship with a relative preservation of the effect over time (Figure 4). Some constituents that are observed as majority in these EOs and which have been reported repellent action against $S$. zeamais are $\alpha$-pinene, and $\beta$-caryophyllene $[14,41]$. It is important to note that these oils cause repellence at concentrations up to 1000 times lower than the fumigation $\mathrm{LC}_{50}$, so their potential use could be focused on grain protection. The repellent effect of EOs is useful in the management of stored grain pests since it contributes to removing insects from the storage zones, resulting in the decrease of the number of eggs and insects and consequent reduction of the losses caused by insects [42].
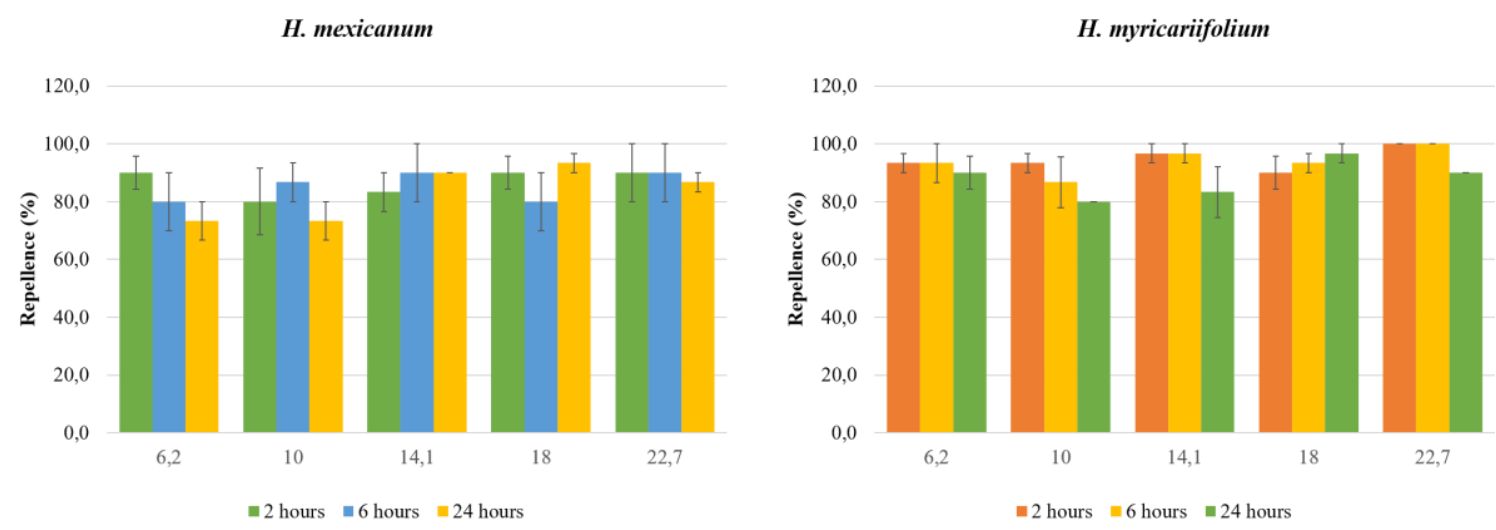

Figure 4. Repellent activity of EOs from species of the Hypericum genus against $S$. zeamais

In conclusion, the present research reported for the first time the chemical composition and insecticidal activity against $S$. zeamais of EOs from $H$. mexicanum, $H$. myricariifolium and $H$. juniperinum. The results indicated that oils were found to be rich in monoterpenes (30.9-54.7\%), sesquiterpenes (27.8-33.7\%), and aliphatic hydrocarbons (23.11-57.6\%). EOs from H. mexicanum and $H$. myricariifolium showed potential to control S. zeamais adults, due these exhibit fumigant toxicity and strong repellence against the insect.

\section{Acknowledgments}

The authors gratefully acknowledge to Universidad Nacional de Colombia (ID 31295), Pontificia Universidad Javeriana (ID PPTA 7364) and MINCIENCIAS for financing with resources from the Fondo Nacional de Financiamiento para la Ciencia, la Tecnología y la Innovación, Francisco José de Caldas through the project with contract 382-2016 and code 120371250800.

\section{Supporting Information}

Supporting information accompanies this paper on http://www.acgpubs.org/journal/records-ofnatural-products

\section{ORCID}

William R. Patiño-Bayona: 0000-0002-5866-0293

Erika Plazas: 0000-0002-4072-667X

Jenifer J. Bustos-Cortes: 0000-0001-5545-7866

Juliet A. Prieto-Rodríguez: 0000-0002-7064-2389

Oscar J. Patiño-Ladino: 0000-0003-1290-7964 


\section{References}

[1] J.F. Kamanula, S.R. Belmain, D. R. Hall, D.I. Farman, D. J. Goyder, B.M. Mvumi and P.C. Stevenson (2017). Chemical variation and insecticidal activity of Lippia javanica (Burm. f.) Spreng essential oil against Sitophilus zeamais Motschulsky, Ind. Crop. Prod. 110, 75-82.

[2] J.H. Lü and Y.Q. He (2010). Fumigant toxicity of Ailanthus altissima swingle, Atractylodes lancea (Thunb.) DC. and Elsholtzia stauntonii Benth extracts on three major stored-grain insects, Ind. Crop. Prod. 32(3), 681-683.

[3] P. Trematerra and S. Savoldelli (2014). Pasta preference and ability to penetrate through packaging of Sitophilus zeamais Motschulsky (Coleoptera: Dryophthoridae), J. Stored Prod. Res. 59, 126-132.

[4] G. O. Babarinde, SA. Babarinde, T.K. Ojediran, A.F. Odewole, D.A. Odetunde and T.S. Bamido (2019). Chemical composition and toxicity of Jatropha curcas seed oil against Sitophilus zeamais Motschulsky as affected by pre-extraction treatment of seeds, Biocatal. Agric. Biotechnol. 21, 101333.

[5] A. Bertoli, B. Conti, V. Mazzoni, L. Meini and L. Pistelli (2012). Volatile chemical composition and bioactivity of six essential oils against the stored food insect Sitophilus zeamais Motsch (Coleoptera Dryophthoridae), Nat. Prod. Res. 26(22), 2063-2071.

[6] M. Kłyś, N. Malejky and M. Nowak-Chmura (2017). The repellent effect of plants and their active substances against the beetle storage pests, J. Stored Prod. Res. 74, 66-77.

[7] I.A. Torres de Araújo, R. da Silva, A. Gomes da Silva, P. Milet-Pinheiro, P.M. Guedes Paiva, D.M. do Amaral Ferraz Navarro, M.V. da Silva, T.H. Napoleão and M. Tereza dos Santos Correia (2020). Chemical characterization and insecticidal effect against Sitophilus zeamais (maize weevil) of essential oil from Croton rudolphianus leaves, Crop Prot. 129, 105043.

[8] M. Butnariu and I. Sarac (2018). Essential oils from plants, JBBS. 1(4),35-43.

[9] K.K. Pradeep, R. Asit, J. Sudipta, K.M. Pradipta and C.P. Pratap (2017). Chemical composition and antioxidant activities of the essential oil of Hypericum gaitii Haines - an endemic species of Eastern India, Nat. Prod. Res. 32(6), 739-742.

[10] T. Üstüner, Ş. Kordali, A.U. Bozhüyük and M. Kesdek (2018). Investigation of pesticidal activities of essential oil of Eucalyptus camaldulensis Dehnh, Rec. Nat. Prod. 12(6), 557-568

[11] M. L. Bhavya, A.G. S. Chandu and S.S. Devi (2018). Ocimum tenuiflorum oil, a potential insecticide against rice weevil with anti-acetylcholinesterase activity, Ind. Crop. Prod. 126, 434-439.

[12] J.L. Rios (2016). Essential oils in food preservation, flavor and safety: Essential oils, Chapter 1 - What they are and how the terms are used and defined. Academic Press, Elsevier; pp. 3-10.

[13] M.B. Isman, S. Miresmailli and C. Machial (2011). Commercial opportunities for pesticides based on plant essential oils in agriculture, industry and consumer products, Phytochem Rev. 10(2), 197-204.

[14] C.K. Karemu, M.W. Ndung'u and M. Githua (2013). Repellent effects of essential oils from selected eucalyptus species and their major constituents against Sitophilus zeamais (Coleoptera: Curculionidae), Int. J. Trop. Insect Sci. 33(3), 188-194.

[15] A.T.H. Mossa (2016). Green pesticides: Essential oils as biopesticides in insect-pest management, $J$. Environ. Sci. Technol. 9(5), 354-378

[16] M.G. Peixoto, L. Bacci, A.F. Blank, A.P.A. Araújo, P.B. Alves, J.H.S. Silva, A.A. Santos, A.P. Oliveria, A.S. da Costa and M. de Fátima Arrigoni-Blank (2015). Toxicity and repellency of essential oils of Lippia alba chemotypes and their major monoterpenes against stored grain insects, Ind. Crop. Prod. 71, 31-36.

[17] H.A. Fouad and C.A.G. Camara (2017). Chemical composition and bioactivity of peel oils from Citrus aurantiifolia and Citrus reticulata and enantiomers of their major constituent against Sitophilus zeamais (Coleoptera: Curculionidae), J. Stored Prod. Res. 73, 30-36.

[18] E. Tozlu, A. Cakir, S. Kordali, G. Tozlu, H. Ozer and T. Aytas Akcin (2011). Chemical compositions and insecticidal effects of essential oils isolated from Achillea gypsicola, Satureja hortensis, Origanum acutidens and Hypericum scabrum against broadbean weevil (Bruchus dentipes), Sci. Hortic. 130, 9-17.

[19] O. S. Da Silva, F. C. da Silva, F.M.C. de Barros, J.L.R. da Silva, S.A. de Loreto Bordignon, V.V.L. EiflerLima and J.S. Prophiro (2013). Larvicidal and growth-inhibiting activities of extract and benzopyrans from Hypericum polyanthemum (Guttiferae) against Aedes aegypti (Diptera: Culicidae), Ind. Crop. Prod. 45, 236-239.

[20] E. Yildirim, M. Kesdek and S. Kordali (2005). Effects of essential oils of three plant species on Tribolium confusum du Val and Sitophilus granarius (L.)(Coleoptera: Tenebrionidae and Curculionidae), Fresenius Environ. Bull. 14, 574-578.

[21] L.A. Mejía-Agudelo, M. Rojas, M. Guerrero-Pabón, F. Ramos, L. Castellanos and J. Marín-Loaiza (2019). Antidepressant-like effects of methanol extract and fractions of Hypericum juniperinum kunth in the forced swimming test, Pharmacogn. Mag. 15(61), 226-231. 
[22] E. A. Plazas (2017). Tamizaje fitoquímico y actividad antibacteriana in vitro de extractos y fracciones de tres especies colombianas del género Hypericum, Rev. Cuba. Plant. Med. 22(1),1-14.

[23] R. P. Adams. (2012). Identification of essential oil components by gas chromatography/mass spectrometry. (4th Ed.). Carol Stream, IL: Allured publishing corporation.

[24] E.E. Stashenko and J.R. Martínez (2010). Algunos aspectos prácticos para la identificación de análitos por cromatografía de gases acoplada a espectrometría de masas, Sci. Chromatogr. 2(1), 29-47.

[25] S. D. Hatipoglu, N. Zorlu, T. Dirmenci, A. C. Goren, T. Ozturk and G. Topcu (2016). Determination of volatile organic compounds in fourty five Salvia species by thermal desorption-GC-MS technique, Rec. Nat. Prod. 10(6), 659-700.

[26] H.A. Makarem, S.E. Kholy, A. Abdel-Latif and A.I. Seif (2015). Physiological and biochemical effects of some essential oils on the granary weevil, Sitophilus granarius (L.)(Coleoptera: Curculionidae), Egypt J. Exp. Biol. (Zool). 11 (2), 117-123.

[27] J.A. Prieto (2012). Estudio fitoquímico de Compsoneura capitellata (Myristicaceae), Zanthoxylum rigidum (Rutaceae) y Ocotea longifolia (Lauraceae) y evaluación de su posible aplicación como biocontroladores de Sitophilus sp., Doctoral thesis. Universidad Nacional de Colombia. pp. 136-138. http://bdigital.unal.edu.co/11391/1/198020-2012.pdf

[28] W. S. Abbott (1925). A method of computing the effectiveness of an insecticide, J. Econ. Entomol. 18(2), 265-267.

[29] M.J. Pascual-Villalobos, M.C. Ballesta-Acosta and A. Soler (2004). Toxicidad y repelencia de aceites esenciales en plagas de almacén del arroz, Bol. San. Veg. Plagas. 30, 279-286.

[30] Z.L. Liu, S.H. Goh and S. H. Ho (2007). Screening of Chinese medicinal herbs for bioactivity against Sitophilus zeamais Motschulsky and Tribolium castaneum (Herbst), J. Stored Prod. Res. 43(3), 290-296.

[31] J. Ringuelet, R. Ocampo, C. Henning, S. Padín, M. Urrutia and G. Dalbello (2014). Actividad insecticida del aceite esencial de Lippia alba (Mill.) N. E. Brown sobre Tribolium castaneum Herbst. en granos de trigo (Triticum aestivum L.), Rev. Bras. Agroecol. 9(2), 214-222.

[32] S Crockett, M. Eberhardt, O. Kunert and W. Schühly (2010). Hypericum species in the Páramos of Central and South America: a special focus upon H. irazuense Kuntze ex N. Robson, Phytochem. Rev. 9(2), 255269.

[33] B. Demirci, K.H.C. Baser, S.L. Crockett and I.A. Khan (2005). Analysis of the volatile constituents of Asian Hypericum L. (Clusiaceae, Hyperidoideae) species, J. Essent. Oil Res. 17(6), 659-663.

[34] Z. Toker, G. Kızıl, H.C. Özen, M. Kızıl and S. Ertekin (2006). Compositions and antimicrobial activities of the essential oils of two Hypericum species from Turkey, Fitoterapia. 77(1), 57-60.

[35] W. Poonsri, W. Pluempanupat, P. Chitchirachan, V. Bullangpoti and O. Koul (2015). Insecticidal alkanes from Bauhinia scandens var. horsfieldii against Plutella xylostella L. (Lepidoptera: Plutellidae), Ind. Crop. Prod. 65, 170-174.

[36] N. M. Sahi (2016). Evaluation of insecticidal activity of bioactive compounds from Eucalyptus citriodora against Tribolium castaneum, Int. J. Pharmacogn. Phytochem. Res. 8(8), 1256-1270.

[37] R.S. Satyan, M. Sakthivadivel, S. Shankar and M.G. Dinesh (2012). Mosquito larvicidal activity of linear alkane hydrocarbons from Excoecaria agallocha L. against Culex quinquefasciatus Say, Nat. Prod. Res. 26(23), 2232-2234.

[38] S. Ma, R. Jia, M. Guo, K. Qin and L. Zhang (2020). Insecticidal activity of essential oil from Cephalotaxus sinensis and its main components against various agricultural pests, Ind. Crop. Prod.150, 112403.

[39] M. H. Badii and V. G. Almanza (2007). Resistencia en insectos, plantas y microorganismos. [Resistance in insects, plants and microorganisms], CULCyT. 4(18), 9-25.

[40] D. Kosini, E.N. Nukenine and K.H. Tofel (2015). Efficacy of Cameroonian Ocimum canum Sims (Lamiaceae) leaf extract fractions against Callosobruchus maculatus (F.)(Coleoptera: Chrysomelidae), infesting Bambara groundnut, J. Entomol. Zool. Stud. 3(5), 487-494.

[41] S. Reis, A. Mantello, J. Macedo, E. Gelfuso, C. da Silva, A. Fachin, A. Cardoso and R. Beleboni (2016). Typical monoterpenes as insecticides and repellents against stored grain pests, Molecules 21(3), 258-268.

[42] L.F. Matos, E. da Cruz Lima, K. de Andrade Dutra, D.M.D.A. Navarro, J.L.R. Alves and G.N. Silva (2020). Chemical composition and insecticidal effect of essential oils from Illicium verum and Eugenia caryophyllus on Callosobruchus maculatus in cowpea, Ind. Crop. Prod. 145, 112088.

[43] S.L. Crockett (2010). Essential oil and volatile components of the genus Hypericum (Hypericaceae), Nat. Prod. Commun. 5(9), 1493-1506.

[44] L.A. Mejía-Agudelo, J.C. Marín-Loaiza and X. Marquínez-Casas (2019). Morfoanatomía e histoquímica de Hypericum juniperinum (Hypericaceae), Rev. Biol. Trop. 67(6), 1160-1169. 
[45] P. Sun, T. Kang, H. Xing, Z. Zhang, D. Yang, J. Zhang, P. W. Paré and M. Li (2019). Phytochemical changes in aerial parts of Hypericum perforatum at different harvest stages, Rec.Nat.Prod. 13(1), 1-9.

[46] N.A.R Tahir, H.A. Azeez, K.A. Muhammad, S.A. Faqe and D.A. Omer (2017). Exploring of bioactive compounds in essential oil acquired from the stem and root derivatives of Hypericum triquetrifolium callus cultures, Nat. Prod. Res. 33(10), 1504-1508.

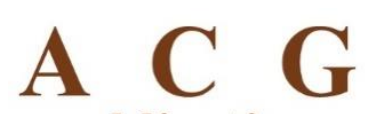

publications

(C) 2020 ACG Publications 